\title{
Characterization and stability evaluation of
}

\section{nanoencapsulated epoxylignans [version 1; peer review: 1 approved, 1 approved with reservations]}

\author{
Yusnita Rifai (D1, Radhia Riski¹, Gemini Alam¹, Magdalena Litaay², \\ Latifah Rahman ${ }^{1}$ \\ ${ }^{1}$ Pharmaceutical Chemistry Laboratory, Faculty of Pharmacy, Hasanuddin University, Makassar, 90245, Indonesia \\ ${ }^{2}$ Biology Department, Faculty of Life Sciences, Hasanuddin University, Makassar, 90245, Indonesia
}

V1 First published: 01 Mar 2018, 7:253

https://doi.org/10.12688/f1000research.13047.1

Latest published: $30 \mathrm{Jul}$ 2018, 7:253

https://doi.org/10.12688/f1000research.13047.2

\section{Abstract}

3',6-dimethoxy-3",4"-(methylenedioxy)-2,5-epoxylignan-4'-ol (DMEO), an epoxylignan isolated from Piper nigrum, has currently captured attention for its potential antitumor effect. However, low stability is limiting its therapeutic application. The application of nanocapsulation would be the main strategy for overcoming this problem. DMEOloaded nanocapsules were prepared by an emulsion-diffusion method using Eudragit RL 100 (at concentrations of 1, 1.5 and 2\%) and polyvinyl alcohol. As the polymer content increased, the encapsulation efficiency and mean particle size also increased. After 6 months of storage at $25^{\circ} \mathrm{C}(0 \% \mathrm{RH})$, no crystalline peaks were observed in the diffraction patterns of all nanocapsules, thereby suggested that the physical stability of nanoencapsulated DMEO was not affected by the concentration ratio of the polymer-stabilizer combinations.

Keywords

nanocapsules, Eudragit RL 100, Glioma, Piper nigrum

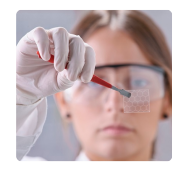

This article is included in the Nanoscience \&

Nanotechnology gateway.

Open Peer Review
Approval Status
version 2
(revision)
30 Jul 2018
version 1
01 Mar 2018
.............................................................
1. Rani Sauriasari, Universitas Indonesia,
Depok, Indonesia
2. Heni Rachmawati, Bandung Institute of
Technology, Bandung, Indonesia
Any reports and responses or comments on the
article can be found at the end of the article.


Corresponding author: Yusnita Rifai (yusnitarifai@gmail.com)

Author roles: Rifai Y: Conceptualization, Formal Analysis, Project Administration, Supervision, Validation, Writing - Original Draft Preparation; Riski R: Investigation, Methodology, Resources, Software; Alam G: Data Curation, Formal Analysis, Resources, Validation; Litaay M: Data Curation, Funding Acquisition, Software, Writing - Review \& Editing; Rahman L: Formal Analysis, Methodology, Resources, Supervision

Competing interests: No competing interests were disclosed.

Grant information: This work was supported by the Ministry of Research, Technology and Higher Education of Indonesia through a grant from WCU-UNHAS 2016-2017.

The funders had no role in study design, data collection and analysis, decision to publish, or preparation of the manuscript.

Copyright: ( 2018 Rifai Y et al. This is an open access article distributed under the terms of the Creative Commons Attribution License, which permits unrestricted use, distribution, and reproduction in any medium, provided the original work is properly cited. Data associated with the article are available under the terms of the Creative Commons Zero "No rights reserved" data waiver (CCO 1.0 Public domain dedication).

How to cite this article: Rifai $Y$, Riski R, Alam G et al. Characterization and stability evaluation of nanoencapsulated epoxylignans [version 1; peer review: 1 approved, 1 approved with reservations] F1000Research 2018, 7:253

https://doi.org/10.12688/f1000research.13047.1

First published: 01 Mar 2018, 7:253 https://doi.org/10.12688/f1000research.13047.1 


\section{Introduction}

The hedgehog (Hh) pathway is required for the growth and proliferation of various cancers ${ }^{1}$. The signaling begins with the binding of $\mathrm{Hh}$ protein ligand to its membrane receptor Ptch, which represses the activity of Smoothened (Smo). Smo in turn promotes the expression of the GLI (Gliomaassociated oncogene) family of transcription factors, leading to tumor development ${ }^{2}$. The direct association of GLI with a specific binding site (5'-GACCACCCA-3') in the promoter region of the target gene has been reported to contribute to pancreatic and prostate cancer cells ${ }^{3}$. We previously reported Hedgehog/GLI inhibitors from various plants ${ }^{4-6}$. We also isolated five lignans $\left(\left(8 R^{*}, 8^{\prime} \mathrm{R}^{*}\right)\right.$-9-hydroxy-3,4-dimethoxy-3',4'-methylenedioxy9,9'-epoxylignan, kusunokinin, haplomyrfolol, dihydroclusin) including a new epoxylignan DMEO from Piper nigrum using the immobilization of GLI-GST on carboxylic acid magnetic dynabeads. DMEO was confirmed to have Hh signaling inhibitory activity and to be selectively cytotoxic against PANC1. Meanwhile the synthetic epoxylignan of DMEO related compound was reported to inhibit the mRNA expression of protein patched homolog (Ptch) in human pancreatic cancer cells (PANC1) and thus is considered to be a prospective drug candidate to treat cancer related to the GLI signaling pathway. However, poor solubility remains the main limitation of $\mathrm{DMEO}^{7}$, hence making drug administration in vivo difficult. The nanoencapsulation of DMEO is one of the ways of overcoming the problem.

Nanoencapsulation techniques are particularly important to protect drugs from degradation in biological fluids and improve their penetration into cells. The techniques are also beneficial for hydrophobic molecules because the ultra-dispersed pharmaceutical dosage forms that nanoencapsulation provides allow rapid drug dissolution ${ }^{8}$. The nanoencapsulation of DMEO within a suitable polymer is considered to be a good way to ameliorate its poor solubility, because the polymer acts as a rate-controlling membrane to obtain the desired controlled release. The physical stability of pure compounds remains the greatest challenge for pharmaceutical scientists seeking to exploit higher solubility properties. A gold standard revealed by the International Council for Harmonization (ICH) stated that physical stability tests of compounds should be performed within accelerated (6 months) and/or long-term (12 months) storage conditions ${ }^{9}$. The physical stability was examined using powder X-ray diffraction (PXRD) analysis.

The objective of this study was to characterize the physical stability of DMEO-loaded nanocapsules, which were optimized by varying the polymer concentration to obtain stable spherical particles. The most stable particles would result from the best concentration ratio between polymers and stabilizers, ultimately improving the dissolution rate of poorly water soluble drugs.

\section{Methods}

Materials

Eudragrit RL 100 and polyvinyl alcohol were purchased from Sigma-Aldrich Ltd. (St Louis, MO, USA). DMEO was obtained from the Pharmaceutical Chemistry Laboratory of Hasanuddin University (Indonesia). Methanol, ethyl acetate, acetonitrile, chlorophorm and demineralized water were purchased from Merck, Indonesia. All chemicals and solvents were of analytical or pharmaceutical grade.

\section{Preparation of nanocapsules}

Nanocapsules were prepared by an emulsion-diffusion method using Eudragit RL (ERL, Merck Ltd) at various concentrations $(1 \%, 1.5 \%$ and $2 \%)$. Briefly, the ERL polymer $(100,150$ and $200 \mathrm{mg}$ ) were dissolved respectively in $10 \mathrm{~mL}$ of ethyl acetate saturated with water. Each of this organic phase was then emulsified with $40 \mathrm{~mL}$ of aqueous phase, saturated with ethyl acetate, containing $300 \mathrm{mg}$ of Polyvinyl alcohol (PVA) using a high speed homogenizer (ultra-turax $\mathrm{T} 25$, Germany) at $1500 \mathrm{rpm}$ for 60 minutes. Deionized water $(150 \mathrm{~mL})$ was then added to the emulsion to induce the diffusion of ethyl acetate into the continuous phase leading to the formation of nanocapsules. The organic solvent and the water phase were evaporated under reduced pressure to obtain a concentrated suspension of $40 \mathrm{~mL}$.

\section{Preparation of DMEO-loaded nanocapsules}

DMEO was previously synthesized and characterized as a white powder ${ }^{10} .10 \mathrm{mg}$ of DMEO was dissolved in $10 \mathrm{~mL}$ of methanol, which was then added to polymerized nanocapsules. The DMEO-loaded nanocapsules were dried in a desiccator until constant weight. They were then kept in a closed glass vial and stored at $25^{\circ} \mathrm{C}$.

\section{Characterization of DMEO-loaded nanocapsules}

The size of DMEO-loaded nanocapsules was analyzed by laser diffraction using a Partica LA-950 laser diffraction particle size analyzer (Horiba Ltd, Japan). Dried particles (5 mg) were dispersed in Miglylol 812 using a UP50H ultrasound processor (Hielscher, Germany) and analyzed in triplicate. The surface characteristics of the particles were observed by scanning electron microscopy (SEM) (Jeol, JSM-5600 LV, Japan). The yields of the particles were calculated by the sum of the weights of all components, discounting the content of water in the suspensions. After stirring the powders in acetonitrile for 90 minutes at room temperature followed by centrifugation and filtration (GVWP membrane, $0.45 \mu \mathrm{m}$, Millipore), the nanoencapsulation efficiency of DMEO was determined by UV-Vis spectroscopy (Shimadzu; $229 \mathrm{~nm}$ absorbance detector). The nanoencapsulation efficiency (\%) of the powder was calculated from the correlation of the theoretical and experimental DMEO concentration. The onset of its crystallization was examined before and after 6 months of storage at $25^{\circ} \mathrm{C}$, using an X-Ray Diffractometer (XRD-7000, SHIMADZU) with $\mathrm{Cu} \mathrm{K} \alpha$ radiation $(\lambda=0.154 \mathrm{~nm})$. The diffraction patterns were analyzed using X'Pert Highscore Plus (version 2.2d).

\section{Results}

SEM analysis reveals that all DMEO-loaded nanocapsules are mostly spherical (Figure 1). As the polymer content increased, the encapsulation efficiency and mean particle size also increased, as seen in Table 1, suggesting that nanoencapsulation minimized deactivation of the drugs during the delivery process due to the protection from the polymer shell. This might 


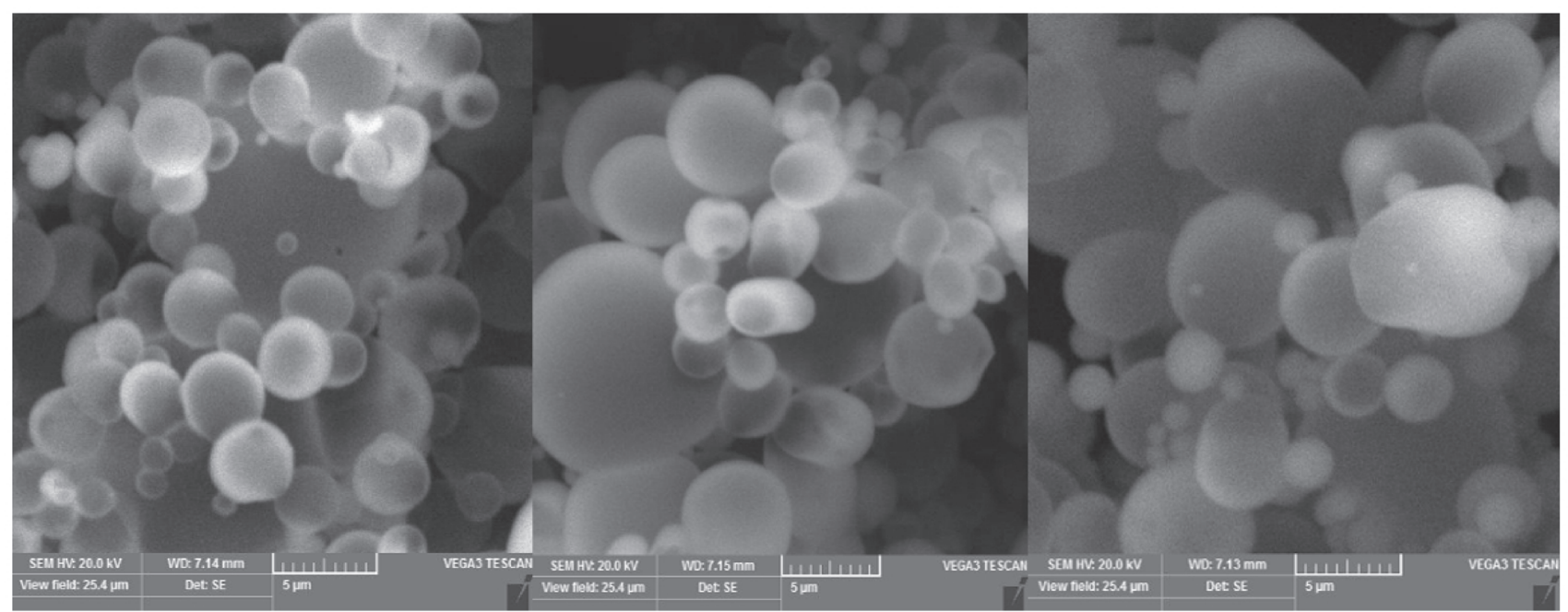

(A)

(B)

(C)

Figure 1. SEM images of sprayed-dried powder in formulations (A) F1 (B) F2 and (C) F3.

\section{Table 1. The observed mean particle sizes and encapsulation efficiencies of DMEO-loaded nanocapsules.}

\begin{tabular}{|l|l|l|l|l|l|}
\hline Sample Code & DMEO (mg) & \multicolumn{2}{|l|}{ Polymer $(\mathbf{m g})$} & $\begin{array}{l}\text { Mean Particle } \\
\text { Size (nm) }\end{array}$ & $\begin{array}{l}\text { Encapsulation } \\
\text { Efficiency (\%) }\end{array}$ \\
\hline PVA & ERL & & \\
\hline F1 & 10 & 300 & 100 & $227.55 \pm 0.231$ & $89.53 \pm 0.307$ \\
\hline F2 & 10 & 300 & 150 & $253.96 \pm 0.012$ & $89.46 \pm 0.211$ \\
\hline F3 & 10 & 300 & 200 & $255.09 \pm 0.455$ & $90.31 \pm 0.352$ \\
\hline
\end{tabular}

ensure sufficient amounts of drug reaching the targeted areas. ERL is a copolymer of partial esters of acrylic acid containing low amounts of a quaternary ammonium group. ERL is a water-soluble polymer that plays a crucial role in controlling drug release because its water uptake characteristic contributes to the swelling of the polymers.

In crystalline materials, atoms are periodically arranged, but in non-crystalline materials, atoms are randomly arranged. Figure 2 shows that the peaks of DMEO do not possess that periodicity, while the characteristic peak falls at $19.3^{\circ} 2 \theta$. After the physical mixtures were subjected to various concentrations of polymers and stabilizers, all the peaks were re-observed at 0 and 6 months of storage. No crystalline peaks were observed in the diffraction patterns, as shown in
Figure 2a, 2b and 2c (upper, down), suggesting that the particles remain spherical throughout the duration of the stability study. The unchanged position of the largest peak of DMEO, which remains at $19.3^{\circ} 2 \theta$ (Figure $2 \mathrm{a}, 2 \mathrm{~b}$ and $2 \mathrm{c}$ (upper, down)), indicates that there is no change in the diffraction pattern of DMEO after 6 months of storage. It is important for the DMEO particles to remain stable during 6 months of storage to ensure that the resulting DMEO-loaded nanocapsules meet the minimal standard requirements of drug formulation stability.

Dataset 1. Raw data for particle size, particle yields, nanoencapsulation efficiencies and X-ray diffraction pattern values

http://dx.doi.org/10.5256/f1000research.13047.d195348 


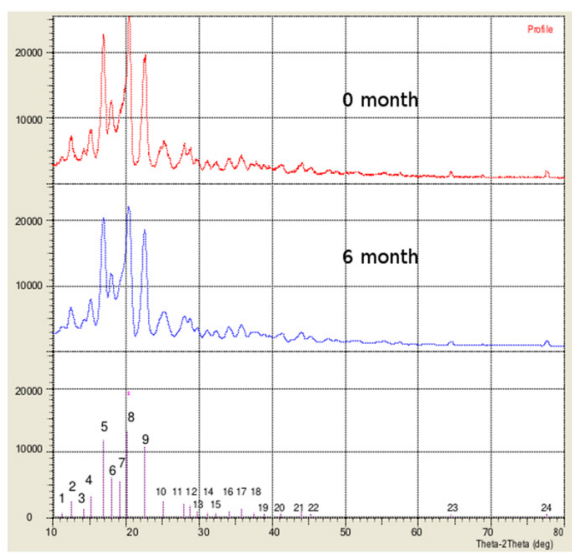

A

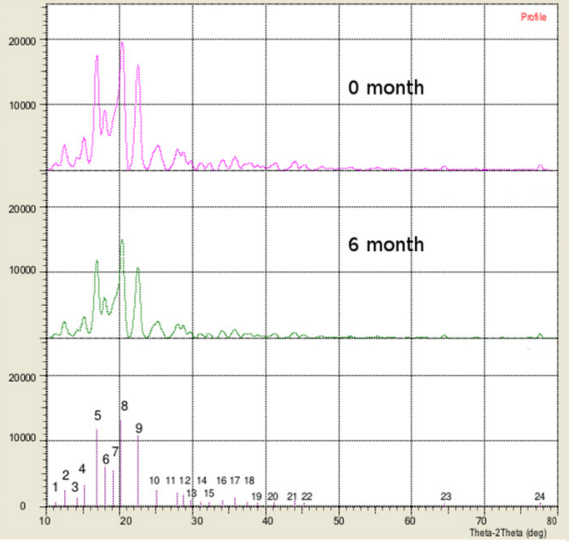

B

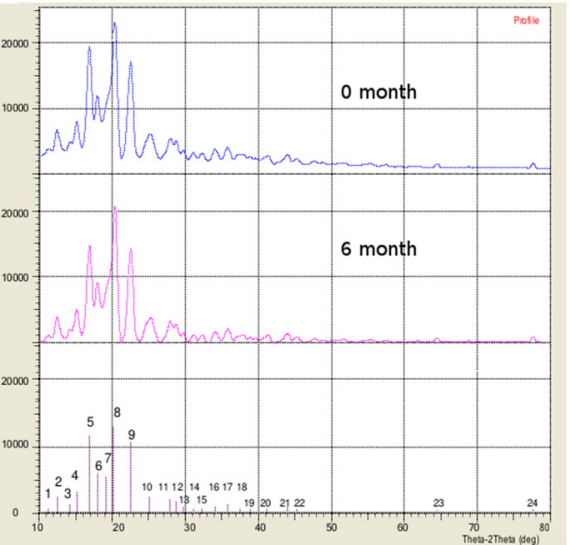

C

Figure 2. (A) X-ray diffraction patterns of DMEO-loaded nanocapsules of F1 after 0 and 6 months of storage (B) X-ray diffraction patterns of DMEO-loaded nanocapsules of F2 after 0 and 6 months of storage (C) X-ray diffraction patterns of DMEO-loaded nanocapsules of F3 after 0 and 6 months of storage.

\section{Discussion}

The polymer-based encapsulation may be beneficial regarding improved short-term physical stability. The nanoencapsulation of DMEO yielded entrapment efficiencies of $89.53 \pm 0.307$, $89.46 \pm 0.211,90.31 \pm 0.352 \%$ with particle sizes of $227.55 \pm 0.231$, $253.96 \pm 0.012$, and $255.09 \pm 0.455 \mathrm{~nm}$, respectively. It is generally considered that higher molecular weight polymers have less entropy loss related to their fast motion, which results in a higher affinity to drug surfaces ${ }^{10}$, and they therefore perhaps have better steric formation. The charge along the polymer chains can build a strong double layer surrounding the particles, granting electrostatic stabilization and therefore smaller particle $\operatorname{size}^{11}$.

The results showed that the polymer concentration influenced the particle size and entrapment efficiency. The $1 \%$ polymer concentration formula (F1) fulfilled the requirement of stable nanocapsules, including spherical and uniform surface morphology. This formula exhibited the greatest percentage of nanocapsules' weight $(10.24 \%)$ but had the smallest particle size $(227.55 \mathrm{~nm})$. Meanwhile, F3 showed the greatest entrapment efficiency $(90.31 \%)$. We chose F1, F2 and F3 for the further physical stability study using XRD to see whether the different concentrations of polymer interfered with the stability of DMEO in nanocapsules. Polymers were expected to adsorb to the surface of the nanocapsules, providing both electrostatic and steric repulsion among particles, therefore producing nanoparticles with decreased particle sizes and improved physical stability. The polymers may adsorb to the drug surfaces through several points along the polymer chains, enabling the loops and tails of the polymers to extend into the liquid medium, providing a steric effect.

The key finding in this work was that higher concentrations of polymer in the stirring solution during the production process yielded higher encapsulation efficiencies and smaller particle sizes. Tuning the polymer ratio was essential to obtaining spherical particles, without necessarily affecting the stability of the obtained nanocapsules.

\section{Data availability}

Dataset 1: Raw data for particle size, particle yields, nanoencapsulation efficiencies and X-ray diffraction pattern values. 10.5256/f1000research.13047.d195348 ${ }^{12}$

\section{Competing interests}

No competing interests were disclosed.

\section{Grant information}

This work was supported by the Ministry of Research, Technology and Higher Education of Indonesia through a grant from WCUUNHAS 2016-2017.

The funders had no role in study design, data collection and analysis, decision to publish, or preparation of the manuscript.

\section{Acknowledgments}

We are grateful to Dahlan Tahir from the Department of Physics, Faculty of Life Sciences for providing necessary research facilities. 


\section{Supplementary material}

Supplementary File 1: Structure of 3',6-dimethoxy-3",4"'-(methylenedioxy)-2,5-epoxylignan-4'-ol (DMEO). ${ }^{1} \mathrm{H}$ and ${ }^{13} \mathrm{C}$ NMR Data of DMEO

Click here to access the data.

1. Lauth $M$, Bergström A, Shimokawa $T$, et al: Inhibition of GLI-mediated transcription and tumor cell growth by small-molecule antagonists. Proc Nat Acad Sci USA. 2007; 104(20): 8455-8460.

PubMed Abstract | Publisher Full Text | Free Full Text

2. Lee $\mathrm{Y}$, Kawagoe R, Sasai $\mathrm{K}$, et al.: Loss of suppressor-of-fused function promotes tumorigenesis. Oncogene. 2007; 26(44): 6442-6447. PubMed Abstract | Publisher Full Text

3. Altaba AR, Sánchez P Dahmane N: Gli and Hedgehog in cancer: tumours, embryos and stem cells. Nat Rev Cancer. 2002; 2(5): 361-367. PubMed Abstract | Publisher Full Text

4. Rifai $\mathrm{Y}$, Arai MA, Koyano $\mathrm{T}$, et al:: Terpenoids and a Flavonoid Glycoside from Acacia pennata Leaves as Hedgehog/GLI-Mediated Transcriptional Inhibitors. J Nat Prod. 2010; 73(5): 995-997. PubMed Abstract | Publisher Full Text

5. Rifai $Y$, Arai MA, Sadhu SK, et al:: New Hedgehog/GLI signaling inhibitors from Excoecaria agallocha. Bioorg Med Chem Lett. 2011; 21(2): 718-722. PubMed Abstract | Publisher Full Text

6. Rifai Y, Arai MA, Koyano T, et al.: Acoschimperoside P, 2'-acetate: a Hedgehog signaling inhibitory constituent from Vallaris glabra. J Nat Med. 2011; 65(3-4): 629-632.

PubMed Abstract | Publisher Full Text
7. Rifai $Y$, Tani HB, Nur M, et al: Synthesis, Molecular Mechanism and Pharmacokinetic Studies of New Epoxy Lignan-Based Derivatives. Arch Pharm (Weinheim). 2016; 349(11): 848-852.

PubMed Abstract | Publisher Full Tex

8. Brigger I, Dubernet $C$, Couvreur P: Nanoparticles in cancer therapy and diagnosis. Adv Drug Deliv Rev. 2002; 54(5): 631-651. PubMed Abstract | Publisher Full Text

9. Huynh-Ba K, Zahn M: Understanding ICH Guidelines Applicable to Stability Testing. Handbook of Stability Testing in Pharmaceutical Development. 2009; $1^{\text {st }} \mathrm{ed}$ New York: Springer. Publisher Full Text

10. Choi JY, Park CH, Lee J: Effect of polymer molecular weight on nanocomminution of poorly soluble drug. Drug Deliv. 2008; 15(5): 347-353. PubMed Abstract | Publisher Full Text

11. Duro R, Alvarez C, Martínez-Pacheco R, et al.: The adsorption of cellulose ethers in aqueous suspensions of pyrantel pamoate: effects on zeta potential and stability. Eur J Pharm Biopharm. 1998; 45(2): 181-188. PubMed Abstract | Publisher Full Text

12. Rifai $Y$, Riski R, Alam G, et al:: Dataset 1 in: Characterization and stability evaluation of nanoencapsulated epoxylignans. F1000Research. 2018. Data Source 


\section{Open Peer Review}

\section{Current Peer Review Status:}

\section{Version 1}

Reviewer Report 23 May 2018

https://doi.org/10.5256/f1000research.14146.r33856

(C) 2018 Rachmawati $\mathbf{H}$. This is an open access peer review report distributed under the terms of the Creative Commons Attribution License, which permits unrestricted use, distribution, and reproduction in any medium, provided the original work is properly cited.

\section{Heni Rachmawati}

School of Pharmacy, Research Center for Nanosciences and Nanotechnology, Bandung Institute of Technology, Bandung, Indonesia

This article describes the strategy to improve the lack of physical characteristic of such natural active compound by developing the nanocarrier system based on polymer. The authors discussed the correlation between polymer concentration and the drug loading efficiency. The main objective as well as the concept is acceptable in term of scientific perspective. However, some lack important information in particular in the method session: how the drug-loaded nanocapsules was formed, the sample preparation on such evaluation e.g PXRD, and the detail on SEM analysis (magnification etc). The important data to conclude the successful approach are missing: solubility and/or dissolution rate. Also, the only PXRD data is not sufficient to conclude the stability issue of the drug-loaded nanocapsules. The description presented in the result section is not sufficient to explain the phenomenon found in this study.

Is the work clearly and accurately presented and does it cite the current literature? Partly

Is the study design appropriate and is the work technically sound? Partly

Are sufficient details of methods and analysis provided to allow replication by others? Partly

If applicable, is the statistical analysis and its interpretation appropriate? Not applicable

Are all the source data underlying the results available to ensure full reproducibility? Partly

Are the conclusions drawn adequately supported by the results? 
Partly

Competing Interests: No competing interests were disclosed.

I confirm that I have read this submission and believe that I have an appropriate level of expertise to confirm that it is of an acceptable scientific standard, however I have significant reservations, as outlined above.

Author Response 23 Jul 2018

Yusnita Rifai, Hasanuddin University, Makassar, Indonesia

Thanks for valuable scientific feedback. We add some more explanation in the method session of the revised manuscript associated with how the drug-loaded nanocapsules are formed, the sample preparation and the detail on SEM analysis (magnification at 600x). As for the preparation of nanocapsules, the DMEO can be encapsulated into nanocapsules at a maximum concentration of $1 \mathrm{mg} / \mathrm{ml}$ with the ratio maintained at the 1:40; 1:45; and 1:50 drug/polymer ratio.

Meanwhile, the diffraction patterns of the DMEO-loaded nanocapsules exhibit a diffraction peak at $19.3^{\circ} 2 \theta$. These results indicate that DMEO-loaded nanocapsules are not present as a crystalline state, but are probably dissolved within the nanocapsule's core. It is noted that the only PXRD data is not sufficient to conclude the stability issue of the drug-loaded nanocapsules, the PXRD data aimed to characterize the crystallinity of DMEO in the formulated nanocapsules.

Competing Interests: No competing interests were disclosed.

Reviewer Report 10 April 2018

https://doi.org/10.5256/f1000research.14146.r31917

(C) 2018 Sauriasari R. This is an open access peer review report distributed under the terms of the Creative Commons Attribution License, which permits unrestricted use, distribution, and reproduction in any medium, provided the original work is properly cited.

\section{Rani Sauriasari}

Department of Pharmacy, Faculty of Pharmacy, Universitas Indonesia, Depok, Indonesia

The overall construct of the manuscript is generally concise. The authors highlight the higher concentrations of polymer in the stirring solution during the production process yielded higher encapsulation efficiencies and smaller particle sizes. However, it is better to add statistical analysis to show the correlation between concentration of polymer with encapsulation efficiency and particle size.

Is the work clearly and accurately presented and does it cite the current literature? 
Yes

Is the study design appropriate and is the work technically sound?

Yes

Are sufficient details of methods and analysis provided to allow replication by others? Yes

If applicable, is the statistical analysis and its interpretation appropriate?

Not applicable

Are all the source data underlying the results available to ensure full reproducibility? Yes

Are the conclusions drawn adequately supported by the results?

Yes

Competing Interests: No competing interests were disclosed.

I confirm that I have read this submission and believe that I have an appropriate level of expertise to confirm that it is of an acceptable scientific standard.

Author Response 23 Jul 2018

Yusnita Rifai, Hasanuddin University, Makassar, Indonesia

Thanks for the valuable feedback. Statistical analysis is important to correctly interpret the data. However, because of the small number of sample formula and their repetitious treatment $(n=3)$, we did not do any statistical analysis.

Competing Interests: No competing interests were disclosed. 
The benefits of publishing with F1000Research:

- Your article is published within days, with no editorial bias

- You can publish traditional articles, null/negative results, case reports, data notes and more

- The peer review process is transparent and collaborative

- Your article is indexed in PubMed after passing peer review

- Dedicated customer support at every stage

For pre-submission enquiries, contact research@f1000.com 